\title{
Supporting recommendations for childhood preventive interventions for primary health care: elaboration of evidence synthesis and lessons learnt
}

\author{
Sophie Jullien ${ }^{1 *}$, Gottfried Huss ${ }^{2}$ and Ralf Weigel ${ }^{3}$
}

\begin{abstract}
Background: Recommendations to prevent morbidity and mortality in children was a high priority for the editorial group of a WHO pocket book for primary health care in the European region. However, the benefit of preventive interventions is not always clear and recommendations differ across countries and institutions. Here, we summarize the existing recommendations and the most recent evidence on ten selected preventive interventions applied to children under five years to inform this group. In addition, we reflect on the process and challenges of developing these summaries.

Methods: For each intervention, we systematically searched for current recommendations from the WHO, the United States Preventive Services Task Force, the workgroup Previnfad from the Spanish Association of Primary Care Pediatrics, the Centers of Disease Control and Prevention, and the National Institute for Health and Care Excellence. Then, we systematically searched the sources above and the Cochrane library for relevant systematic reviews. For each topic, we reported the recommendations and the strength of the recommendation when and as reported by the authors. We summarized the main findings of systematic reviews with the certainty of the evidence as reported. Categorising the ten preventive interventions in three groups allowed narrative comparisons between similar types of interventions and between groups.
\end{abstract}

Results and discussion: For the single interventions of providing vitamins $D$ and $K$ and topical fluoride there is overall a high degree of consensus between institutions for the evidence of their effectiveness. For the multiple interventions to prevent sudden infant death syndrome and unintentional injuries consensus was more variable as evidence of effectiveness is harder to ascertain. For the screening interventions the summaries of recommendations and evidence varied too. While institutions generally agreed in recommending for vision screening and against universal screening for language and speech delay and iron deficiency, they had some differences for pulse oximetry and autism.

The transparent and independent process shed light upon how institutions use existing evidence in their settings common and different positions were accounted for and became visible. We also identified gaps and duplications of research. Our approach was a crucial starting point for developing the respective sections in the pocket book.

Keywords: Prevention, Screening, Child, Evidence-based medicine

\footnotetext{
* Correspondence: sophjullien@gmail.com

'Barcelona Institute for Global Health, University of Barcelona, Barcelona, Spain

Full list of author information is available at the end of the article
}

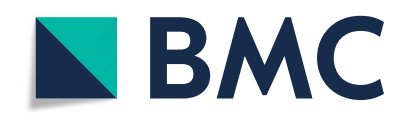

(- The Author(s). 2021 Open Access This article is licensed under a Creative Commons Attribution 4.0 International License, which permits use, sharing, adaptation, distribution and reproduction in any medium or format, as long as you give appropriate credit to the original author(s) and the source, provide a link to the Creative Commons licence, and indicate if changes were made. The images or other third party material in this article are included in the article's Creative Commons licence, unless indicated otherwise in a credit line to the material. If material is not included in the article's Creative Commons licence and your intended use is not permitted by statutory regulation or exceeds the permitted use, you will need to obtain permission directly from the copyright holder. To view a copy of this licence, visit http://creativecommons.org/licenses/by/4.0/. The Creative Commons Public Domain Dedication waiver (http://creativecommons.org/publicdomain/zero/1.0/) applies to the data made available in this article, unless otherwise stated in a credit line to the data. 


\section{Background}

Preventable morbidity and mortality among children constitute a critical global health matter. Preventive interventions are specific population- and individualbased interventions, which aim to protect, promote, and maintain health and well-being, and to minimize the burden of diseases, associated risk factors and disability [1]. Preventive care of children has a potentially huge benefit in decreasing childhood preventable morbidity and mortality. In the last decades, a broad list of preventive interventions targeting infants and children has been developed and implemented in the different health systems. While some of those interventions are evidence-based practice with proven benefit, others are common practice based on common sense or expert opinion, without clear evidence justifying effectiveness or benefit, resulting potentially in controversy. Each preventive intervention is however delivered at a cost for both the families and the health systems. There is a need to determine the safety and effectiveness of controversial preventive interventions, to optimize the protection of children and to optimize the use of limited health resources.

The World Health Organization (WHO) European Region is developing a new pocket book for primary health care for children and adolescents in Europe. To this end, the Integrated Management of Childhood Illness (IMCI) and recommendations around common childhood diseases are being revised, so that the pocket book provides updated recommendations applicable to the European setting, to ensure provision of quality services at primary health care level.

In this review, we aimed to summarize the existing recommendations and the most recent evidence on ten selected preventive interventions applied to children under 5 years of age to inform the WHO editorial group to make recommendations for health promotion in primary health care. The ten selected preventive interventions were: vitamin $\mathrm{D}$ prophylaxis in infancy, vitamin $\mathrm{K}$ prophylaxis in newborns, prophylaxis of caries with fluoride for children under 5 years, sudden infant death syndrome (SIDS) prevention, prevention of unintentional injuries in children under 5 years, vision screening in newborns and early childhood, newborn screening for critical congenital heart defects, screening of iron deficiency anaemia in early childhood, screening for autistic spectrum disorder (ASD) in early childhood, and screening for language and speech delay in children under 5 years.

In addition, we reflected on the process and challenges of developing recommendations based on available evidence and other determining factors, according to the type of recommendations.

\section{Methods}

\section{Selection process of topics}

The list of preventive interventions that we reviewed is neither an exclusive nor a comprehensive selection of preventive interventions for children under 5 years of age. We selected preventive interventions suitable for primary health care settings common in the European region, and applicable to primary health care physicians including paediatricians and other primary care providers. We followed a multi-step process with the aim to select most relevant topics for child health where evidence of benefit is controversial and for which evidence synthesis is most needed for decision making.

1. Pre-selection of preventive interventions: during the autumn meeting of the European Confederation of Primary Care Paediatricians (ECPCP) in October 2018 in Vilnius the 25 delegates representing ten countries completed a survey about the estimated magnitude of the benefit of 22 preventive interventions.

2. Exclusion of the interventions with high consensus on benefit: a steering group reviewed the survey results and identified six interventions with high consensus of benefit and decided to focus on those with controversial benefit.

3. The steering group presented survey findings to the WHO editorial core team of the pocket book to reach a final consensus and selected ten preventive interventions for evidence synthesis, based on priority research and feasibility criteria including time constraint.

\section{Formulation of key questions}

For each topic, we formulated several key questions following the Participants, Intervention, Comparison, Outcomes (PICO) format whenever this was applicable. The main focus of the key questions addresses the effectiveness of the preventive interventions. We also assessed the balance between benefits and harms of the preventive interventions whenever this was applicable and feasible.

\section{Search methods}

Firstly, we gathered existing recommendations for each preventive intervention, from sources we deemed relevant with potential applicability to the European context. We then intended to gather all available evidence to assess effectiveness and safety of the preventive interventions. We developed a research protocol that includes the search methods prior to starting the search. 


\section{Identification and selection of recommendations}

For each topic, we systematically searched for current recommendations from the WHO, the United States Preventive Services Task Force (USPSTF), the workgroup PrevInfad from the Spanish Association of Primary Care Pediatrics (AEPap), the Centers for Disease Control and Prevention (CDC) in the US, and the UK's National Institute for Health and Care Excellence (NICE) websites, by using key words (specified for each topic in the corresponding article) and by manual search [2-6]. We limited the search from the 1st January 2010 up to November 2019 and identified recommendations regardless of language. These websites as well as the references from the identified recommendations were checked for systematic reviews or relevant studies supporting their statements. In the case of USPSTF, we also checked the recommendations in progress for identification of any recommendations to be published soon.

We selected these sources in agreement with the expert group members in charge of developing the preventive chapter for the WHO pocket book for primary childcare. For topics with no or a limited number of recommendations by the above institutions and sources, we searched for additional sources that we cited in the corresponding article.

\section{Identification and selection of supporting evidence}

We systematically searched for systematic reviews commissioned or cited by the WHO, USPSTF, PrevInfad and NICE to inform their recommendations, published from 2010 up to date. For each topic, we also searched the Cochrane library for identification of relevant systematic reviews, by using key terms in titles, abstracts and keywords [7]. We screened titles and abstracts of the reviews retrieved from the search strategy for considering inclusion in this document, before looking at full-text reviews. We included all reviews addressing the topic as per the research question established. We also screened the Cochrane protocols retrieved by the search strategy, to identify systematic reviews to be potentially published in the near future. When a protocol was identified, we contacted the authors to enquire the status of the review and the intended date of publication of the systematic review. When no systematic review was found on a particular topic from the above sources, we considered including reviews published earlier than 2010 and conducted a literature search in Pubmed to identify any relevant review or trial. These additional resources were included as considered by the author of each topic so that a complete summary of the existing literature could be presented for each topic; they are cited in the corresponding articles.

\section{Data collection and data synthesis Summary of recommendations}

For each topic, we cited the recommendations identified from the different sources and the strength of the recommendation when and as reported by the authors. USPSTF classifies their recommendations in one out of five grades to describe the strength of the recommendation (Table 1) [8]. PrevInfad uses either the USPSTF method or the Grading of Recommendations Assessment, Development and Evaluation (GRADE) methodology and classifies their recommendations as strong or weak [9]. NICE considers the strength of the recommendation based on the GRADE approach; however, it is only reflected in the wording of the recommendation itself. Indeed, the words such as 'offer', 'measure', 'advise' or 'refer' are used in NICE documents to reflect a strong recommendation, while 'consider' is used to reflect a recommendation for which the trade-off between desirable and undesirable effects is less certain [10]. We specified in each article the methods used for grading the recommendations whenever it differed from the above methods.

\section{Summary of the evidence}

We summarized the main findings of systematic reviews in a narrative way and in summary tables. We also reported the certainty of the evidence as reported by the review authors. Cochrane authors used the GRADE approach for assessing the certainty of the evidence [11]. This consists of assessing several factors for each important and critically important outcome. Five factors can lower the certainty of the body of evidence: limitations in study design and execution, indirectness, imprecision, inconsistency and publication bias; and three factors can increase the certainty of the body of the evidence from observational studies: dose-response gradient, direction of plausible bias and magnitude of the effect. The certainty of the evidence is graded as high, moderate, low and very low for each assessed outcome. Authors of reviews commissioned by the USPSTF used another method developed by the USPSTF. It is based on the number, quality, size of studies, consistency of results among studies, and directness of the evidence, to grade the aggregate internal validity (quality) of the body of evidence for each key question as good, fair, or poor [8] (Table 2).

No statistical analysis was performed from the gathered evidence.

\section{Groups of preventive interventions for narrative synthesis}

We classified the ten preventive interventions into three groups, to allow narrative comparisons among similar types of interventions, and for reflection on the process 
Table 1 Grade recommendations from the USPSTF [8]

\begin{tabular}{|c|c|c|}
\hline Grade & Definition & Suggestions for practice \\
\hline$A$ & $\begin{array}{l}\text { The USPSTF recommends the service. There is high certainty that the } \\
\text { net benefit is substantial. }\end{array}$ & Offer or provide this service. \\
\hline B & $\begin{array}{l}\text { The USPSTF recommends the service. There is high certainty that the } \\
\text { net benefit is moderate or there is moderate certainty that the net } \\
\text { benefit is moderate to substantial. }\end{array}$ & Offer or provide this service. \\
\hline C & $\begin{array}{l}\text { The USPSTF recommends against routinely providing the service. } \\
\text { There may be considerations that support providing the service in an } \\
\text { individual patient. There is at least moderate certainty that the net } \\
\text { benefit is small. }\end{array}$ & $\begin{array}{l}\text { Offer or provide this service only if other considerations support the } \\
\text { offering or providing the service in an individual patient. }\end{array}$ \\
\hline D & $\begin{array}{l}\text { The USPSTF recommends against the service. There is moderate or } \\
\text { high certainty that the service has no net benefit or that the harms } \\
\text { outweigh the benefits. }\end{array}$ & Discourage the use of this service. \\
\hline I & $\begin{array}{l}\text { The USPSTF concludes that the current evidence is insufficient to } \\
\text { assess the balance of benefits and harms of the service. Evidence is } \\
\text { lacking, of poor quality, or conflicting, and the balance of benefits } \\
\text { and harms cannot be determined. }\end{array}$ & $\begin{array}{l}\text { Read the clinical considerations section of USPSTF Recommendation } \\
\text { Statement. If the service is offered, patients should understand the } \\
\text { uncertainty about the balance of benefits and harms. }\end{array}$ \\
\hline
\end{tabular}

and the challenges of developing recommendations based on available evidence:

- Single pharmacological interventions for preventing undesirable outcomes (primary prevention): vitamin D supplementation for preventing rickets and infections, vitamin $\mathrm{K}$ for preventing haemorrhage disease of the newborn, and fluoride for preventing dental caries.

- Multiple interventions for preventing an undesirable outcome (primary prevention): interventions addressing risk factors and promoting beneficial measures for preventing SIDS and unintentional injuries.

- Screening interventions to detect a condition early (secondary prevention): vision screening in newborns and early childhood, use of pulse oximetry for newborn screening of critical congenital heart defects, screening of iron deficiency anaemia, screening for ASD, and screening for language and speech delay.

\section{Results}

We present the evidence synthesis for each of the ten preventive interventions in separate articles of this Supplement, including a comprehensive list of references of all the included sources. Table 3 summarizes the source and date of existing recommendations. For most topics, USPSTF and PrevInfad provided clear recommendations and supporting documents (systematic reviews) for informing their decisions. Although most of the topics were addressed by the CDC and NICE, accessing the documents supporting their recommendations was difficult, mostly due to a lack of references. We did not find WHO recommendations for three topics.

We summarized the main characteristics of the supporting evidence (such as source of the evidence and main findings), the certainty of the evidence, the recommendations across the reviewed documents and the strength of the recommendations in Tables 4, 5 and 6.

\section{Single interventions for preventing an undesirable outcome}

Three articles of this Supplement reviewed single interventions. We found that all the international institutions we looked at (including the WHO, PrevInfad, NICE and European consensus) recommend supplementation with vitamin $\mathrm{D}$ for preventing rickets, administration of vitamin $\mathrm{K}$ for preventing the haemorrhage disease of the newborn, and use of topical fluoride for preventing caries. The strength of the recommendation for the main statement is strong or grade B for each intervention and is based on moderate to high certainty of the evidence for vitamin D supplementation and use of fluoride.

Table 2 Assessment of the quality of the evidence by USPSTF [8]

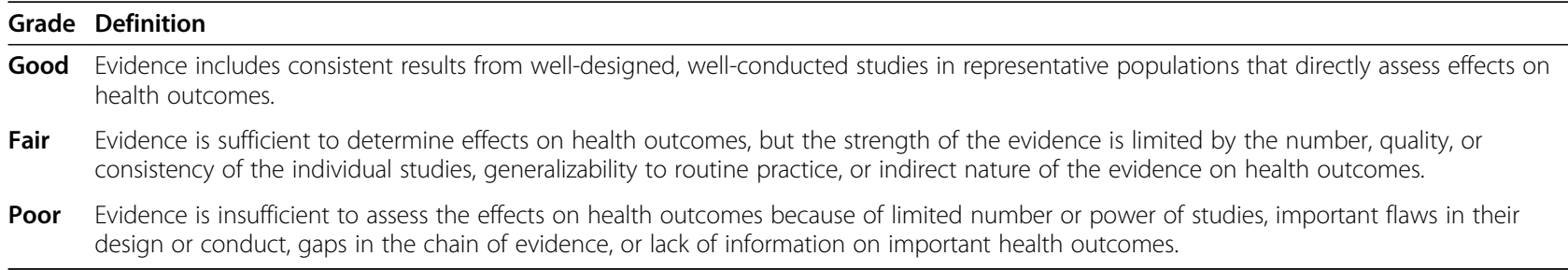


Table 3 Source and date of existing recommendations

\begin{tabular}{|c|c|c|c|c|c|c|c|}
\hline Types of interventions & Interventions & WHO & USPSTF & Prevlnfad & CDC & NICE & Others \\
\hline \multirow[t]{3}{*}{ Single interventions } & Vitamin D & 2019 & No & $2009^{a}$ & 2018 & 2008 & Global consensus, 2016 \\
\hline & Vitamin K & 2017 & No & $2010^{\mathrm{a}}$ & 2018 & 2015 & $\begin{array}{l}\text { ESPGHAN, } 2016 \\
\text { CADTH, } 2015\end{array}$ \\
\hline & Fluoride & 2018 & $2014^{a}$ & $2011^{a}$ & 2001 & 2014 & $\begin{array}{l}\text { AAP, } 2014 \\
\text { NHS, } 2017\end{array}$ \\
\hline \multirow[t]{2}{*}{ Multiple interventions } & SIDS & $A A P^{b}$ & $A A P^{b}$ & $2016^{a}$ & $A A P^{b}$ & 2015 & AAP, $2016^{\mathrm{a}}$ \\
\hline & Unintentional injuries ${ }^{c}$ & NA & NA & NA & NA & NA & NA \\
\hline \multirow[t]{5}{*}{ Screening interventions } & Vision screening & No & $2017^{\mathrm{a}}$ & $2016^{a}$ & 2019 & 2015 & $\begin{array}{l}\text { AAP, } 2016 \\
\text { RCPCH, } 2019 \\
\text { UK NSC, } 2013\end{array}$ \\
\hline & Pulse oximetry for CCHD screening & No & No & No & 2018 & 2015 & $\begin{array}{l}\text { AAP, } 2019 \\
\text { AEP, } 2018 \\
\text { RCPCH, } 2019 \\
\text { UK NSC, } 2014\end{array}$ \\
\hline & IDA screening & 2001 & $2015^{\mathrm{a}}$ & $2011^{a}$ & 1998 & No & $\begin{array}{l}\text { AAP, } 2010 \\
\text { UK NSC, } 2017\end{array}$ \\
\hline & ASD screening & 2019 & $2016^{a}$ & $2017^{a}$ & 2015 & $2013^{d}$ & $\begin{array}{l}\text { AAP, } 2015 \\
\text { CTFPHC, } 2019 \\
\text { UK NSC, } 2012\end{array}$ \\
\hline & Language and speech delay screening & No & $2015^{\mathrm{a}}$ & $2017^{e}$ & $2019^{d}$ & No & $\begin{array}{l}\text { CTFPHC, } 2016^{\mathrm{e}} \\
\text { RCPCH, } 2019\end{array}$ \\
\hline
\end{tabular}

Abbreviations: AAP American Academy of Pediatrics, AEP Spanish Paediatric Association (Asociación Española de Pediatría), ASD Autistic spectrum disorder, CADTH Canadian Agency for Drugs and Technologies in Health, CCHD Critical congenital heart defects, CDC Centers of Disease Control and Prevention, CTFPHC Canadian Task Force on Preventive Healthcare, ESPGHAN European Society for Paediatric Gastroenterology Hepatology and Nutrition, IDA Iron deficiency anaemia, NA Not applicable, NHS National Health Service, NICE National Institute for Health and Care Excellence, RCPCH Royal College of Paediatrics and Child Health, SIDS Sudden infant death syndrome, UK NSC United Kingdom National Screening Committee, USPSTF United States Preventive Services Task Force, WHO World Health Organization

${ }^{\text {a }}$ These sources include both recommendations and supporting evidence through an independent systematic review

${ }^{b}$ These institutions support and refer to the AAP recommendations for this topic

'Due to the extent of this topic, a different approach was used for evidence synthesis. See corresponding article

${ }^{\mathrm{d}}$ Some information in this topic, although no clear recommendations were found

eDocuments on the broader area of developmental delay

Between the three interventions (vitamin D, vitamin $\mathrm{K}$ and topical fluoride), there are substantial differences in the time when trials or systematic reviews that support the evidence were conducted. For example, studies assessing the effectiveness of vitamin $\mathrm{K}$ for preventing the haemorrhage disease of the newborn were conducted in the 1960s and 1990s, while assessment of the use of topical fluoride for preventing caries come from more recent trials (up to 2014) with a systematic review conducted in 2019.

Although all institutions recommend these interventions in general, we noted a lack of data and an overall lower certainty of the evidence to inform specific aspects for each of these three interventions including doses and duration of supplementation. For example, there is a lack of evidence to inform whether vitamin D supplementation should be given only during the first 12 months of life or beyond, to inform what is the optimal regimen of oral vitamin $\mathrm{K}$ (doses and number of doses), or to inform which fluoride concentration is optimal in toothpastes for preventing caries and for limiting adverse effects.

\section{Multiple interventions for preventing an undesirable outcome}

Two articles of this Supplement assessed the impact of several interventions for preventing either SIDS or unintentional injuries. In both cases, there were no randomised controlled trials (RCTs) and the evidence came from retrospective analyses (mainly case-control studies) and surveillance data only. Certainty of the evidence varied from low (mainly) to high, and the strength of the recommendation varied from strong to weak or insufficient (A, B, C, D or I) for the risk factors assessed. Overall, the different institutions recommend similar preventive interventions based on the available evidence and good practice recommendations based on common sense.

Screening interventions for early detection of a disorder Five articles of this Supplement summarize the evidence and existing recommendations for screening interventions.

For vision screening, we found that all the institutions we looked at recommend screening all newborns for 
Table 4 Summary of evidence and recommendations for single interventions

\begin{tabular}{|c|c|c|c|c|c|c|c|}
\hline \multirow[b]{2}{*}{ Intervention } & \multicolumn{4}{|l|}{ Evidence } & \multicolumn{3}{|c|}{ Recommendations } \\
\hline & Type of interventions & $\begin{array}{l}\text { Types of } \\
\text { studies }\end{array}$ & Date & Findings & $\begin{array}{l}\text { Certainty of } \\
\text { the evidence }^{a}\end{array}$ & $\begin{array}{l}\text { Recommendations } \\
\text { across reviewed } \\
\text { documents }\end{array}$ & $\begin{array}{l}\text { Strength of } \\
\text { recommendations }^{a}\end{array}$ \\
\hline \multirow[t]{2}{*}{ Vitamin D } & $\begin{array}{l}\text { Effectiveness of vit D } \\
\text { supplementation for } \\
\text { preventing nutritional } \\
\text { rickets in term born } \\
\text { children (clinical and } \\
\text { radiological outcomes) }\end{array}$ & $\begin{array}{l}\text { SR (4 trials, } \\
1700 \\
\text { participants) } \\
\text { RCT } \\
\text { Surveillance } \\
\text { data }\end{array}$ & $\begin{array}{l}\text { SR } 2007 \\
\text { Studies } \\
1994 \text { to } \\
2004\end{array}$ & $\begin{array}{l}\text { Vit D } \\
\text { supplementation } \\
\text { prevents from } \\
\text { developing } \\
\text { rickets }\end{array}$ & $\begin{array}{l}\text { High quality } \\
\text { evidence } \\
\text { according to } \\
\text { European global } \\
\text { consensus }\end{array}$ & \multirow{2}{*}{$\begin{array}{l}\text { - WHO: } \\
\text { acknowledges } \\
\text { effectiveness, but } \\
\text { requests further } \\
\text { research for } \\
\text { specific } \\
\text { recommendations } \\
\text { - Previnfad, CDC, } \\
\text { NICE, Global } \\
\text { European } \\
\text { consensus } \\
\text { recommend }\end{array}$} & \multirow[t]{2}{*}{$\begin{array}{l}\text { - WHO: category } 2 \\
\text { intervention } \\
\text { - PrevInfad: Grade B } \\
\text { - European global } \\
\text { consensus: strong }\end{array}$} \\
\hline & $\begin{array}{l}\text { Effectiveness of vit D } \\
\text { supplementation for } \\
\text { improving bone mineral } \\
\text { density (BMD) }\end{array}$ & $\begin{array}{l}\text { SR (6 RCTs, } \\
884 \\
\text { participants) }\end{array}$ & $\begin{array}{l}\text { SR } 2010 \\
\text { Studies } \\
2004 \text { to } \\
2008\end{array}$ & $\begin{array}{l}\text { No effect on } \\
\text { total body BMD } \\
\text { or lumbar spinal } \\
\text { BMD. } \\
\text { Probably no } \\
\text { effect on hip } \\
\text { BMD and } \\
\text { forearm BMD. }\end{array}$ & $\begin{array}{l}\text { High certainty } \\
\text { evidence } \\
\text { Moderate } \\
\text { certainty } \\
\text { evidence }\end{array}$ & & \\
\hline \multirow[t]{3}{*}{ Vitamin K } & $\begin{array}{l}\text { Effectiveness of vit } \mathrm{K} \text { for } \\
\text { preventing HDN (clinical } \\
\text { outcome: bleeding) }\end{array}$ & $\begin{array}{l}\text { SR }(2 \text { RCTs, } \\
\text { only for } \\
\text { classical } \\
\text { HDN and } \\
\text { IM) }\end{array}$ & $\begin{array}{l}\text { Studies } \\
\text { 1960's }\end{array}$ & Effective & \multirow{2}{*}{$\begin{array}{l}\text { Not graded by } \\
\text { Cochrane } \\
\text { authors but } \\
\text { referred as 'poor } \\
\text { methodological } \\
\text { quality' } \\
\text { Graded as low- } \\
\text { moderate by } \\
\text { WHO }\end{array}$} & \multirow[t]{3}{*}{$\begin{array}{l}\text { Recommended by } \\
\text { all institutions }\end{array}$} & \multirow[t]{3}{*}{$\begin{array}{l}\text { Strong (WHO, } \\
\text { Previnfad) }\end{array}$} \\
\hline & $\begin{array}{l}\text { Effectiveness of vit K for } \\
\text { preventing HDN } \\
\text { (biochemical outcomes) }\end{array}$ & $\begin{array}{l}\text { SR (5 RCTs, } \\
\text { only for } \\
\text { classical } \\
\text { HDN, IM } \\
\text { and oral) }\end{array}$ & $\begin{array}{l}\text { Studies } \\
\text { 1990's }\end{array}$ & Effective & & & \\
\hline & Intramuscular versus oral & $\begin{array}{l}\text { No RCT } \\
\text { National } \\
\text { surveillance } \\
\text { data }\end{array}$ & $\begin{array}{l}\text { Last } 3 \\
\text { decades }\end{array}$ & $\begin{array}{l}\text { Both } \\
\text { intramuscular } \\
\text { and oral effective }\end{array}$ & Not applicable & & \\
\hline Fluoride & $\begin{array}{l}\text { Toothbrushing for } \\
\text { preventing dental caries }\end{array}$ & SRs & $\begin{array}{l}\text { SR } 2019 \\
\text { Studies } \\
1982 \text { to } \\
2014\end{array}$ & Effective & Moderate & $\begin{array}{l}\text { Recommended by } \\
\text { all institutions }\end{array}$ & $\begin{array}{l}\text { B recommendation } \\
\text { (USPSTF); strength } \\
\text { of the evidence I } \\
\text { (NHS) }\end{array}$ \\
\hline
\end{tabular}

Abbreviations: BMD Bone mineral density, CDC Centers of Disease Control and Prevention, HDN Haemorrhage disease of the newborn, NHS National Health Service, NICE National Institute for Health and Care Excellence, RCT Randomized control trial, SR Systematic review, USPSTF United States Preventive Services Task Force, vit Vitamin

${ }^{\mathrm{a}}$ As per the authors of the retrieved documents

congenital cataract and retinoblastoma through ocular inspection and red reflex examination. Although the screening has low sensitivity, it is a harmless examination that is widely accepted due to the severity of both diseases, and both diseases clearly benefit from early detection and treatment. All institutions also recommend vision screening among children between three and 5 years of age, based on indirect evidence of moderate net benefit.

All the institutions we looked at recommend against universal screening for detecting iron deficiency anaemia and against universal screening for detecting language and speech delay (or make the statement of insufficient evidence to assess the balance of benefits and harms of screening for language and speech delay). The strength of the recommendation for both screening interventions was judged as strong, and was based on the lack of a suitable screening tool and the lack of evidence of benefits from early interventions applied to children detected by screening. The American Academy of Pediatrics is the exception, and recommends universal screening for detecting iron deficiency anaemia despite the lack of evidence.

For the remaining two screening interventions, institutions have discrepant views. Some institutions do not recommend pulse oximetry in all newborns because its less than optimal sensitivity leads to false positive results that require unnecessary referral of cases representing a burden to families and the health system. Institutions recommending it however argue that most of the patients with false positive tests may have other severe clinical conditions and would benefit from prompt recognition and treatment, at least within the first $24 \mathrm{~h}$ of life. Views of institutions on universal screening for detecting ASD are conflicting too. Although screening tools do identify children aged 12 to 36 months with ASD accurately, and small studies show a benefit of early treatment, no evidence on the effectiveness of 
Table 5 Summary of evidence and recommendations for multiple interventions to prevent SIDS and unintentional injuries

\begin{tabular}{|c|c|c|c|c|c|c|c|}
\hline \multirow[b]{2}{*}{$\begin{array}{l}\text { Preventable } \\
\text { outcomes }\end{array}$} & \multicolumn{4}{|l|}{ Evidence } & \multicolumn{3}{|c|}{ Recommendations } \\
\hline & $\begin{array}{l}\text { Type of } \\
\text { interventions }\end{array}$ & $\begin{array}{l}\text { Types of } \\
\text { studies }\end{array}$ & Date & Findings & $\begin{array}{l}\text { Certainty of the } \\
\text { evidence }^{\text {a }}\end{array}$ & $\begin{array}{l}\text { Recommendations } \\
\text { across reviewed } \\
\text { documents }\end{array}$ & $\begin{array}{l}\text { Strength of } \\
\text { recommendations } s^{a}\end{array}$ \\
\hline SIDS & $\begin{array}{l}\text { Supine position } \\
\text { Firm surface } \\
\text { Overheating, } \\
\text { head covering } \\
\text { Room-sharing, } \\
\text { bed-sharing } \\
\text { Breastfeed on } \\
\text { demand } \\
\text { Pacifier nap and } \\
\text { bedtime } \\
\text { Etc. }\end{array}$ & $\begin{array}{l}\text { No RCTs } \\
\text { Case-control } \\
\text { studies } \\
\text { National pre } \\
\text { and post } \\
\text { intervention } \\
\text { data }\end{array}$ & $\begin{array}{l}\text { Most studies } \\
\text { between } 1990 \\
\text { and } 2004\end{array}$ & $\begin{array}{l}\text { See } \\
\text { corresponding } \\
\text { article (https:// } \\
\text { doi.org/10. } \\
1186 / \mathrm{s} 12887- \\
\text { 021-02536-z) }\end{array}$ & $\begin{array}{l}\text { Overall low } \\
\text { certainty of the } \\
\text { evidence, but not } \\
\text { for all risk factors }\end{array}$ & $\begin{array}{l}\text { Overall, similar } \\
\text { recommendations } \\
\text { from the different } \\
\text { institutions }\end{array}$ & $\begin{array}{l}\text { A, B, C, I, not } \\
\text { graded depending } \\
\text { on the risk factors }\end{array}$ \\
\hline $\begin{array}{l}\text { Unintentional } \\
\text { injuries }\end{array}$ & $\begin{array}{l}\text { Against road } \\
\text { traffic injuries: } \\
\text { child restraint } \\
\text { system, helmet, } \\
\text { safety education } \\
\text { of pedestrians, } \\
\text { etc. } \\
\text { Against } \\
\text { drowning: pool } \\
\text { fencing, life } \\
\text { jackets, close } \\
\text { supervision at all } \\
\text { times, etc. } \\
\text { Against } \\
\text { poisoning: } \\
\text { packaging, } \\
\text { secure storage, } \\
\text { poison control } \\
\text { centres, etc. } \\
\text { Against thermal } \\
\text { injuries: smoke } \\
\text { alarms, control } \\
\text { of hot water, } \\
\text { non-flammable } \\
\text { fabrics, etc. } \\
\text { Against falls: } \\
\text { safety } \\
\text { equipment, } \\
\text { protective } \\
\text { equipment, } \\
\text { supervision, etc. }\end{array}$ & $\begin{array}{l}\text { No RCTs } \\
\text { Retrospective } \\
\text { studies } \\
\text { Surveillance } \\
\text { data }\end{array}$ & $\begin{array}{l}\text { Variable, see } \\
\text { corresponding } \\
\text { article (https:// } \\
\text { doi.org/10. } \\
\text { 1186/s12887- } \\
021-02517-2 \text { ) }\end{array}$ & $\begin{array}{l}\text { See } \\
\text { corresponding } \\
\text { article (https:// } \\
\text { doi.org/10. } \\
\text { 1186/s12887- } \\
\text { 021-02517-2) }\end{array}$ & $\begin{array}{l}\text { Overall low } \\
\text { certainty of the } \\
\text { evidence, many } \\
\text { recommendations } \\
\text { based on good } \\
\text { clinical practices. }\end{array}$ & $\begin{array}{l}\text { Overall, similar } \\
\text { recommendations } \\
\text { from the different } \\
\text { institutions }\end{array}$ & $\begin{array}{l}\text { A, B, C, I, not } \\
\text { graded depending } \\
\text { on the risk factors }\end{array}$ \\
\hline
\end{tabular}

Abbreviations: RCT Randomized control trial, SIDS Sudden infant death syndrome

${ }^{\mathrm{a}}$ As per the authors of the retrieved documents

interventions applied to children with ASD detected through screening was found.

\section{Discussion}

Overall, we found that there is high consensus among institutions for recommending single preventive interventions, for which there is moderate to high evidence that such interventions are effective. However, for these single interventions, the lack of data or the low certainty of the evidence regarding doses, frequency or duration of supplementation results into less clear recommendations and ultimately lesser consensus between institutions. Indeed, while no institution is arguing that vitamin $\mathrm{K}$ is effective for preventing haemorrhagic disease of the newborn, national policies are recommending different regimens with regard to route, dose and frequency. This is likely to be explained by the limited data from studies that would directly compare different regimens. In this case, we acknowledge that prospective and comparative trials are challenging to be conducted in the future, due to the low incidence of the outcome and above all due to the severity of the outcome.

For SIDS and unintentional injuries, assessing the effectiveness of preventive interventions is difficult due to the nature of the outcome (death or severe morbidity) and the multiple causes involved. For obvious ethical reasons, no RCT can be performed to assess the impact 


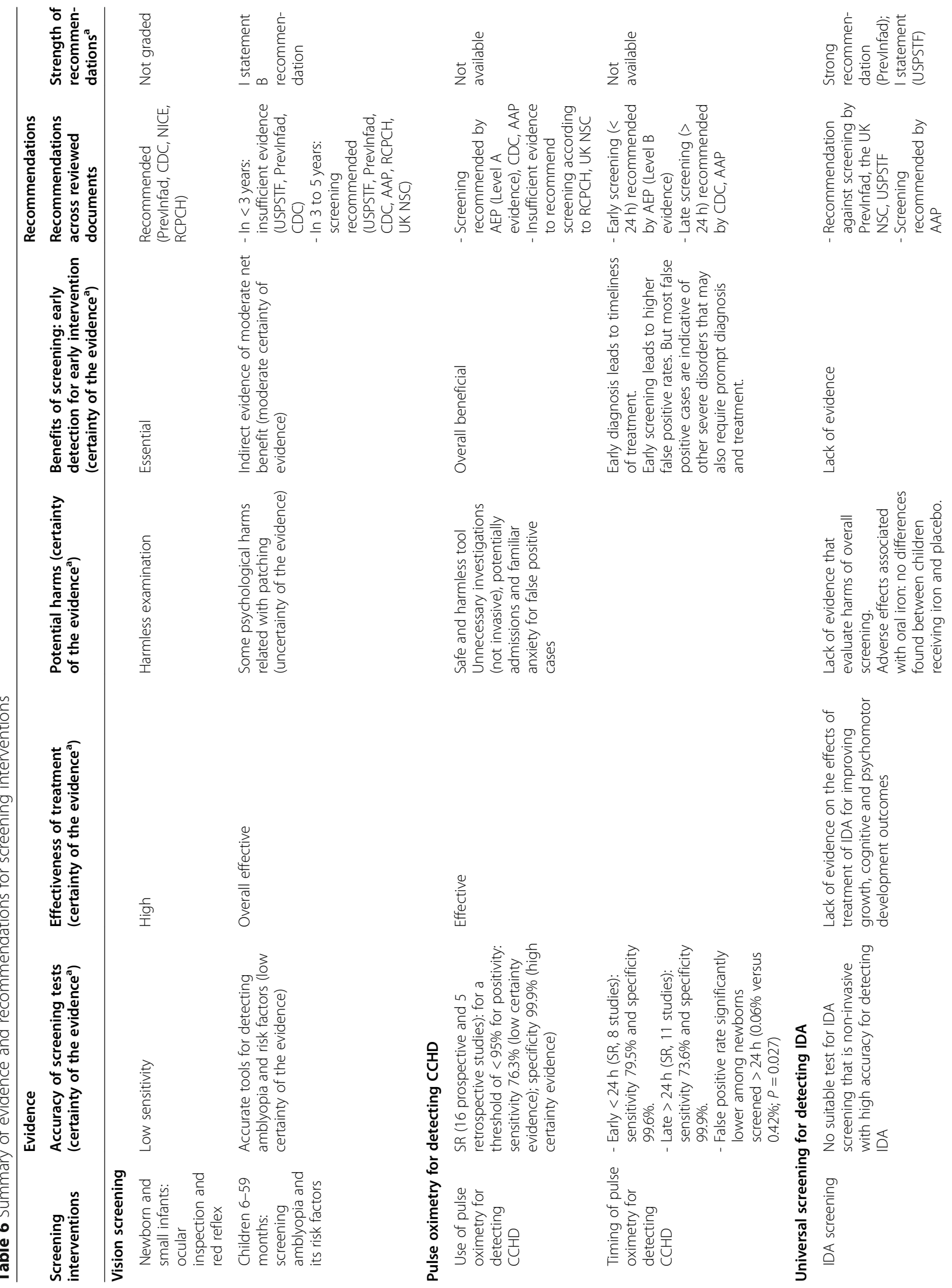




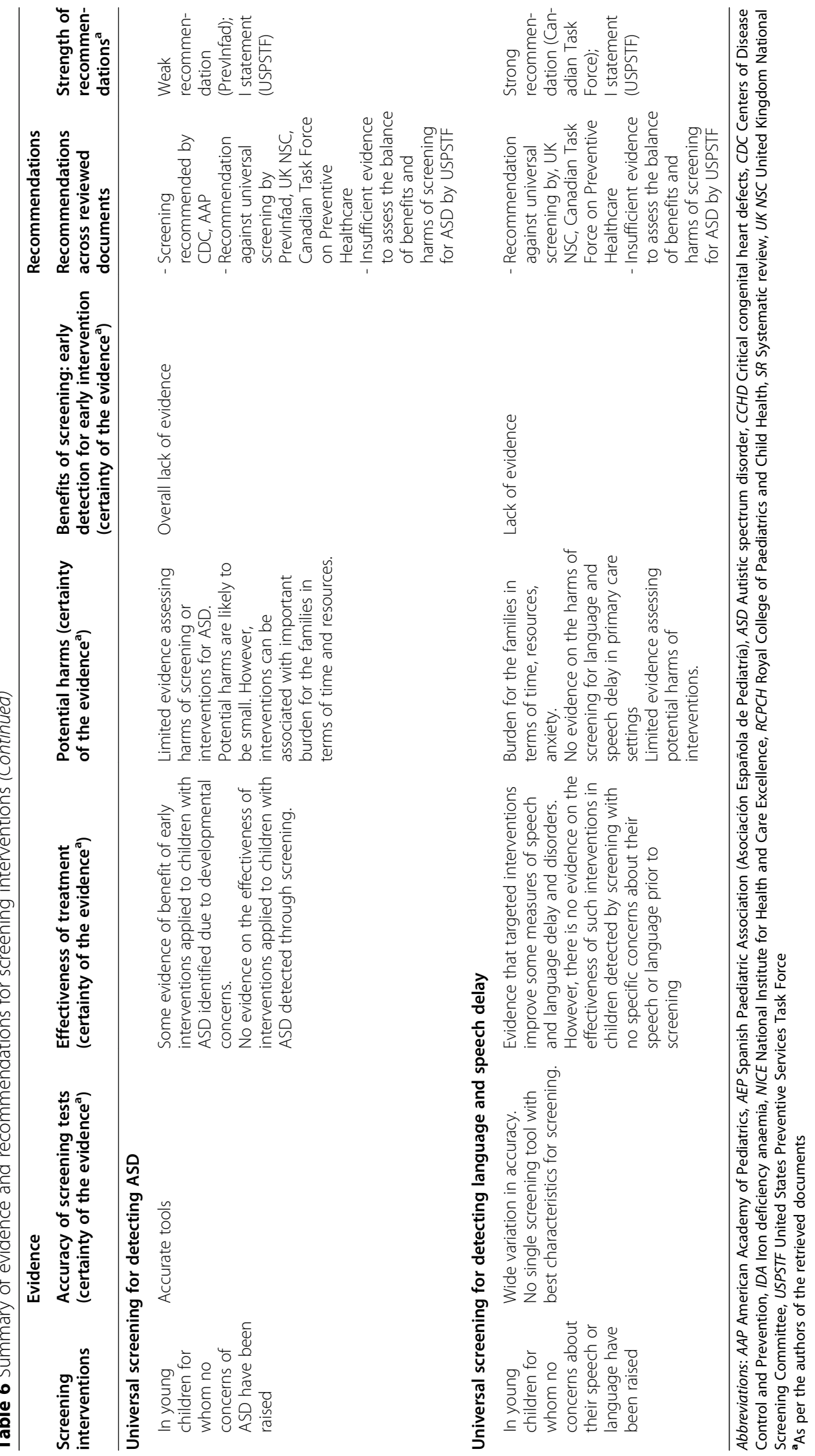


of selected risk factors on the outcome. Evidence is therefore mainly based on retrospective case control studies and surveillance data. This leads to difficulties in differentiating associations from causality between risk factors and outcomes. Furthermore, the multi-causality of the outcome (several risk factors are associated with the outcome) adds difficulties in establishing the contribution of each risk factor. In addition to the association between risk factors and the outcome (SIDS or unintentional injuries), there is overall limited evidence assessing the effect of the recommendations through knowledge, attitude and practices.

The assessment of screening tools seemed to be more controversial than for the single or multiple interventions, with a higher degree of disagreement between institutions. This is likely to be explained by the fact that more aspects must be considered when evaluating the balance between benefits and harms of universal screening than of single interventions. For interventions, the main factors to assess and balance are the effectiveness of the intervention to prevent the undesirable outcome and potential adverse effects associated with the intervention. In contrast, for screening, there is a need to assess the effectiveness of the screening tool to detect the condition, the potential harms derived from the screening tool and treatment, and the treatment effectiveness. In addition, outcomes following early detection and treatment versus the time of presenting signs or symptoms must be considered. Furthermore, the significance and consequences of false positive and false negative cases vary between settings with different prevalence of the disease and with different health care system. As the complete set of criteria for a good screening programme that was adopted by the WHO needs to be assessed, economic and other health system related factors need consideration too [12].

Apart from the immediate findings, the approach we used for this evidence synthesis is valuable in several other ways.

First, providing both aspects (summaries of existing recommendations and evidence) transparently and independently informs clinicians, researchers and policymakers about important research gaps. Where are formal systematic reviews required and where is field research needed? When we reviewed preventive interventions, it became clear that field research through new trials is needed most. Examples are trials to elucidate the optimal duration of vitamin D supplementation for preventing rickets, studies to determine the benefits of early detection and treatment of children with ASD compared with those identified with developmental concern, or research to find a suitable screening tool for iron deficiency anaemia.

Second, the review proved to be a unique opportunity to summarize what is already known across ten controversial and highly important preventive interventions for child health in a single document. It is a crucial starting point when a group or institution intends to develop or update recommendations. Indeed, this approach not only allows the identification of research gaps, but also areas for which recent systematic reviews have already been conducted and areas for which no further evidence might be required. In addition, we noticed that sometimes several institutions committed their own systematic reviews in order to inform the development or update of a recommendation, leading to several groups conducting independent systematic reviews in parallel and addressing the same research question. This represents a potentially avoidable duplication of work, wasting resources.

Third, our approach may facilitate ownership of the prevention chapters in the pocket book by institutions such as paediatric societies. We systematically looked at existing recommendations from credible European institutions, national and international, but also nonEuropean institutions, for generalizable and applicable conclusions. By taking into consideration their views and positions and by making our methods clear, the content of the final product may become more acceptable to the target audience. Moreover, presenting an overview of the existing recommendations also sheds light on how various European institutions use and apply existing evidence to their settings - common and different approaches and positions become visible.

Finally, we complemented the European-focused summary of existing recommendations with an independent body of evidence from relevant systematic reviews of the Cochrane library. Separating the evidence from the recommendations allows the editorial group to gauge how different institutions considered factors such as acceptability, feasibility, potential harms, cost and others.

This review has limitations. There was a limited timeline that was defined by the editorial group and editorial process of the WHO pocket book. To address this, a single author was identified for conducting the literature search, data extraction and data synthesis. When we found no systematic review addressing one of our key questions, or when a systematic review was found but was outdated, it was not possible to conduct a needed systematic review ourselves. In addition, it was not possible to assess the methodological quality of included systematic reviews and guidelines using the AMSTAR-2 tool and the AGREE tool respectively.

The strengths of this review are the alignment to the principles of good evidence synthesis for policy - inclusive, rigorous, transparent and accessible [13, 14]. This review is inclusive, comprising of a range of relevant sources for both available evidence and recommendations. We believe that findings are relevant and useful to 
policymakers, especially for guiding those involved in the health promotion in primary health care for the paediatric pocket book for the WHO European Region. Although these evidence summaries do not assess external validity, we focused on gathering relevant sources from the European or similarly applicable settings when it comes to recommendations. The editorial group is invited to take this into consideration when moving from evidence to recommendations. We used a systematic and rigorous approach for all the topics. The study was conducted by an independent author and peer-reviewed for ensuring good quality. We developed a protocol prior to the evidence synthesis, reported the methods we followed, and acknowledged the limitations of our work with transparency. Finally, timeliness is key, and despite the time constraint, this compilation of evidence synthesis was made available in due time for its use by the WHO paediatric pocket book panel.

\section{Conclusions}

The practice of well childcare in European countries consists of promotion of healthy nutrition and lifestyles and different methods in primary and secondary prevention of diseases. The rationale for this supplement is a response to a concrete need: to provide a WHO editorial group with a summary of evidence about selected preventive interventions with controversial benefit from a wide range of resources. This paper describes the methods used in each of the following articles, summarizes and analyses the existing recommendations and the underlying evidence for single and multiple preventive interventions and screening. In addition, it identifies lessons learnt from the process that might be useful for similar endeavours.

\section{Supplementary Information}

The online version contains supplementary material available at https://doi. org/10.1186/s12887-021-02638-8

Additional file 1. List of abbreviations.

\section{Acknowledgments}

We are very grateful to María Jesús Esparza and Laura Reali for carefully reviewing and providing valuable feedback for each topic.

\section{About this supplement}

This article has been published as part of BMC Pediatrics Volume 21, Supplement 1 2021: Defined preventive interventions for children under five years of age: evidence summaries for primary health care in the $\mathrm{WHO}$ European region. The full contents of the supplement are available at https://bmcpediatrics.biomedcentral.com/articles/supplements/volume-21supplement-1.

\section{Authors' contributions}

SJ was identified as the researcher in the development of the synthesis of evidence and writing the report. For each selected topic on preventive interventions, SJ defined the key questions, established and run the literature search, screened the returned manuscripts for eligibility, extracted data and summarized the existing recommendations and supporting evidence. $\mathrm{GH}$ and RW were the principal advisors of this project. For this introductory article, SJ and RW conceived the idea and wrote the manuscript. All authors have read and approved the final version of all the manuscripts included in the supplement.

\section{Funding}

Publication charges for this article have been funded by the Friede Springer endowed professorship for Global Child Health at the Witten Herdecke University, Germany.

Availability of data and materials

Not applicable.

\section{Declarations}

Ethics approval and consent to participate

Not applicable.

\section{Consent for publication}

Not applicable.

\section{Competing interests}

SJ had a contract and was paid as an independent consultant by the WHO via Witten/ Herdecke University, ECPCP and EPA/UNEPSA for developing the different articles of this Supplement.

$\mathrm{GH}$ and RW are participants of the editorial group of the WHO pocket book.

\section{Author details}

${ }^{1}$ Barcelona Institute for Global Health, University of Barcelona, Barcelona, Spain. ${ }^{2}$ Free public child health Consultant, European Confederation of Primary Care Paediatricians, Lyon, France. ${ }^{3}$ Friede Springer endowed professorship for Global Child Health, Witten Herdecke University, Witten, Germany.

Published: 8 September 2021

\section{References}

1. WHO. Health promotion and disease prevention through population-based interventions, including action to address social determinants and health inequity. 2019. [cited 2019 Jun 7]. Available from: http://www.emro.who. int/about-who/public-health-functions/health-promotion-diseaseprevention.html.

2. National Institute for Health and Care Excellence. NICE guidance. 2019 [cited 2019 Oct 11]. Available from: https://www.nice.org.uk/guidance

3. Centers for Disease Control and Prevention. Centers for Disease Control and Prevention. 2019 [cited 2019 Oct 11]. Available from: https://www.cdc.gov/

4. PrevInfad Group. Recomendaciones PrevInfad/PAPPS. 2019 [cited 2019 Oct 11]. Available from: http://previnfad.aepap.org/

5. US Preventive Services Task Force. USPSTF Published recommendations. 2019 [cited 2019 Oct 11]. Available from: https://www.uspreventiveservicesta skforce.org/BrowseRec/Index/browse-recommendations

6. World Health Organization. World Health Organization. [cited 2019 Oct 11]. Available from: https://www.who.int

7. Cochrane Community. Cochrane library. Cochrane Database of Systematic Reviews. 2019 [cited 2019 Oct 11]. Available from: https://www.cochra nelibrary.com/

8. USPSTF. The Guide to Clinical Preventive Services. 2012.

9. Guyatt GH, Oxman AD, Vist GE, Kunz R, Falck-Ytter Y, Alonso-Coello P, et al. GRADE: an emerging consensus on rating quality of evidence and strength of recommendations. BMJ (British Med Journal). 2008;336:924-6.

10. NICE. Developing NICE guidelines: the manual. 2018 [cited 2021 Mar 2]. Available from: https://www.nice.org.uk/process/pmg20/chapter/writing-theguideline

11. Guyatt GH, Schünemann HJ, Djulbegovic B, Akl EA. Guideline panels should not GRADE good practice statements. J Clin Epidemiol. 2015;68(2015):597600. https://doi.org/10.1016/j.jclinepi.2014.12.011.

12. Wilson J, Jungner G. Principles and practice of screening for disease: Public Health Papers; 1968. [cited 2019 Aug 18]. Available from: https://apps.who. int/iris/bitstream/handle/10665/37650/WHO_PHP_34.pdf? sequence=17 
13. Donnelly CA, Boyd I, Campbell P, Craig C, Vallance P, Walport M, et al. Four principles to make evidence synthesis more useful for policy. Nature. 2018; 558(7710):361-4. https://doi.org/10.1038/d41586-018-05414-4.

14. The Royal Society. The Academy of Medical Sciences. Principles for good evidence synthesis for policy; 2018. p. 1-5. [cited 2021 Mar 2]. Available from: royalsociety.org/evidence-synthesis

\section{Publisher's Note}

Springer Nature remains neutral with regard to jurisdictional claims in published maps and institutional affiliations.

- fast, convenient online submission

- thorough peer review by experienced researchers in your field

- rapid publication on acceptance

- support for research data, including large and complex data types

- gold Open Access which fosters wider collaboration and increased citations

- maximum visibility for your research: over $100 \mathrm{M}$ website views per year

At BMC, research is always in progress. 